\title{
Short communication: The effect of ruminal administration of 5-hydroxy-L-tryptophan on circulating serotonin concentrations
}

\author{
M. K. Connelly, ${ }^{1} \odot$ A. M. Marshall, ${ }^{2}$ P. M. Crump, ${ }^{1}$ and L. L. Hernandez ${ }^{1 *}{ }^{1}$ \\ ${ }^{1}$ Department of Dairy Science, University of Wisconsin, Madison 53706 \\ ${ }^{2}$ Amelgo LLC, Covington, KY 41011
}

\begin{abstract}
The monoamine serotonin has been shown to regulate peripartal calcium homeostasis in multiparous cows and be a possible mitigation tool for hypocalcemia. Increasing circulating serotonin concentrations via prepartum intravenous (IV) administration of the serotonin precursor 5-hydroxy-L-tryptophan (5-HTP) increases postpartum calcium concentrations. However, the ability of 5-HTP to be used orally or ruminally to alter circulating serotonin concentrations has not been established. Hence, our objective was to determine if ruminal administration of 5 -HTP altered circulating serotonin concentrations. Four ruminally cannulated, nonlactating, nonpregnant multiparous Holstein dairy cows were randomly assigned to 1 of 4 treatments in a 4 $\times 4$ replicated Latin square with 4 -d periods separated by a 7 -d washout. On d 1 and 2 of each period, cows were dosed with 1 of 4 experimental treatments as follows: (1) $0 \mathrm{mg} / \mathrm{kg}$ of body weight (BW) of 5 -HTP, (2) $1 \mathrm{mg} / \mathrm{kg}$ of BW of intraruminal $5-\mathrm{HTP}$, (3) $2 \mathrm{mg} / \mathrm{kg}$ of BW of intraruminal 5 -HTP, or (4) $1 \mathrm{mg} / \mathrm{kg}$ of BW of IV 5-HTP. Infusions were administered over a 1-h period, and all groups not receiving 5-HTP IV were infused with an equal volume of IV saline to that of IV $1 \mathrm{mg} / \mathrm{kg}$ of BW of 5 -HTP treatment. Continuous serial blood samples were collected beginning after $\mathrm{d}$ 2 of treatment administration. Whole blood serotonin concentrations were higher in cows dosed with $2 \mathrm{mg} / \mathrm{kg}$ of BW of intraruminal 5-HTP immediately after dosing when compared with cows dosed with $0 \mathrm{mg} / \mathrm{kg}$ of BW of 5 -HTP on d 2, but were similar on d 3 and 4 of the experimental period. Cows receiving IV 5 -HTP had the highest circulating serotonin concentrations relative to all other treatments. These findings demonstrated that 2 intraruminal dosings of 5-HTP at $2 \mathrm{mg} / \mathrm{kg}$ of BW resulted in elevated circulating serotonin concentrations relative to the control immediately after dosing. This
\end{abstract}

Received December 27, 2019.

Accepted July 7, 2020.

*Corresponding author: llhernandez@wisc.edu supports the potential for 5-HTP to be used orally to manipulate circulating serotonin concentrations.

Key words: serotonin, calcium, 5-hydroxy-Ltryptophan, ruminal dosing

\section{Short Communication}

Serotonin is an evolutionarily conserved monoamine that has been demonstrated to regulate a variety of physiological functions. Serotonin is synthesized in a 2-step process originating from the AA L-tryptophan. L-Tryptophan is converted to 5-hydroxy-L-tryptophan (5-HTP) via the enzyme tryptophan hydroxylase, and then 5-HTP undergoes decarboxylation by the enzyme aromatic AA decarboxylase to produce serotonin (Mohammad-Zadeh et al., 2008). Because serotonin is incapable of crossing the blood-brain barrier, each pool of serotonin (neuronal and nonneuronal) is largely considered to be distinctly separate from one another and have independent functions (Walther and Bader, 2003). Traditionally, research has focused on serotonin's action as a neurotransmitter, but as of late, research has demonstrated serotonin's action in energy metabolism, mammary gland homeostasis, gastrointestinal health, and bone metabolism (Berger et al., 2009; Lavoie et al., 2017). It is of particular interest to understand serotonin's role in calcium homeostasis in the dairy cow (Laporta et al., 2013, 2014; Weaver et al., 2016; Slater et al., 2018). However, the efficacy of oral administration of 5-HTP to manipulate serotonin in the dairy cow is unknown and is a crucial prerequisite before conducting large-scale experiments evaluating the potential of 5 -HTP as a dietary management strategy.

The peripartal period is characterized by a large increase in calcium demand at the onset of milk synthesis. Due to the rapid increase in milk synthesis and demand by the mammary gland, dysregulation of calcium metabolism may occur, resulting in low blood calcium concentrations (hypocalcemia) in the peripartum cow (Goff et al., 2002). Interestingly, on d 1 of lactation, serotonin has been shown to positively correlate with blood calcium and parathyroid hormone-related protein 
(PTHrP) concentrations (Laporta et al., 2013). Dietary and oral mitigation tools are often used to help reduce the prevalence of hypocalcemia. Our laboratory demonstrated that increasing circulating serotonin concentrations prepartum via intravenous (IV) administration of the serotonin precursor 5-HTP increased bone mobilization and improved calcium concentrations postpartum (Weaver et al., 2016; Slater et al., 2018). Together, these data suggest that serotonin is involved in the stimulation of negative feedback required to aid bone mobilization and calcium homeostasis in the peripartal cow and may be a novel way to mitigate hypocalcemia incidence within the dairy industry.

Altering circulating serotonin poses challenges due to the rate-limiting step in serotonin synthesis and serotonin's short half-life. Interestingly, supplementation of rumen-protected tryptophan, the precursor to 5-HTP, in dairy cows and heifers increased blood tryptophan, but did not alter blood serotonin concentrations (Kollmann et al., 2008). Oral administration of 5-HTP, the rate-limiting precursor to serotonin, has been shown to be clinically effective at increasing serotonin concentrations in humans because it bypasses the rate-limiting step to directly increase serotonin's biosynthesis (Birdsall, 1998). Use of 5-HTP as a dietary supplement has alleviated symptoms associated with low serotonin concentrations (Javelle et al., 2020). In humans, 5-HTP has been shown to be well-absorbed in oral doses, with approximately $70 \%$ ending up in the bloodstream (Magnussen and Nielsen-Kudsk; 1980; Magnussen et al., 1981). Recently, the effectiveness of orally administered 5-HTP to increase circulating serotonin concentrations relative to control has been demonstrated in preweaned dairy calves, which are considered nonruminants, via daily supplementation of $90 \mathrm{mg} / \mathrm{d}$ of 5-HTP (Marrero et al., 2019). However, dairy calves have yet to commence rumen fermentation, and degradation of AA by rumen microbes in an adult ruminant may pose a challenge when giving oral 5-HTP.

Manipulation of the serotonergic axis and corresponding alterations in calcium homeostasis has been demonstrated via IV infusion of 5-HTP. However, the ability of 5-HTP to be administered ruminally, absorbed, and converted to serotonin is still unknown. Thus, the objective of this study was to determine if ruminal administration of 5-HTP would alter circulating serotonin concentrations in the dairy cow. We hypothesized that ruminal dosing of 5-HTP would alter circulating serotonin concentrations.

All experimental procedures used in this study were approved by the College of Agriculture and Life Sciences Animal Care and Use Committee at the University of Wisconsin-Madison. Care and use protocol guidelines (A005678) were strictly followed for this experiment. Cows were housed in an enclosed tiestall barn at the Dairy Cattle Center at the University of Wisconsin-Madison. Four ruminally cannulated, nonlactating, nonpregnant multiparous (average lactation number $3.25 \pm 0.49 ; \pm$ SEM) Holstein dairy cows were used in a $4 \times 4$ replicated Latin square $(\mathrm{n}=8 /$ treatment) with 2 consecutive days of 5 -HTP administration and serial blood sampling until $72 \mathrm{~h}$ post-termination of the second treatment administration, resulting in 4-d experimental periods. Cows were fed the common herd dry cow TMR ad libitum, consisting of $49.8 \%$ corn silage, $30.4 \%$ straw, and $19.8 \%$ concentrate and mineral mix on a DM basis (DM: $47.5 \pm 2.4 \%, \mathrm{CP}: 20.5 \pm$ $1.2 \%$ DM, ADF: $20.4 \pm 1.2 \%$ DM, NDF: $29.1 \pm 0.9 \%$ $\mathrm{DM}$, and $\left.\mathrm{NE}_{\mathrm{L}}: 1.52 \pm 0.04 \mathrm{Mcal} / \mathrm{kg}\right)$. Daily DMI was recorded. During the washout period, cows were given daily access to exercise for approximately $1 \mathrm{~h}$. The experiment included a 7-d washout period between each subsequent experimental period. Cows were randomly assigned to 1 of 4 treatments. Experimental treatments were: $0 \mathrm{mg} / \mathrm{kg}$ of BW of 5 -HTP $(\mathbf{0 ~} \mathbf{~ m g} / \mathbf{k g} \mathbf{5}$-HTP), $1 \mathrm{mg} / \mathrm{kg}$ of BW of 5 -HTP dosed intraruminal (IR; $\mathbf{1}$ $\mathbf{m g} / \mathbf{k g}$ IR 5 -HTP), $2 \mathrm{mg} / \mathrm{kg}$ of BW of 5 -HTP dosed IR (2 $\mathrm{mg} / \mathrm{kg}$ IR 5 -HTP $)$, and $1 \mathrm{mg} / \mathrm{kg}$ of BW of 5-HTP IV infusion ( $\mathbf{1} \mathbf{~} \mathbf{m g} / \mathbf{k g}$ IV $\mathbf{5}$-HTP $)$. All experimental treatments except $1 \mathrm{mg} / \mathrm{kg}$ IV 5 -HTP received an IV solution of saline equivalent to that of the 1 $\mathrm{mg} / \mathrm{kg}$ IV 5-HTP treatment. Preparation of 5-HTP for IV treatment was performed as previously reported (Weaver et al., 2016; Slater et al., 2018). Experimental dosings of 5-HTP (H9772, Sigma-Aldrich, St. Louis, $\mathrm{MO})$ were calculated on a milligram per kilogram of BW basis of each cow receiving treatment and mixed until solution. Body weights were recorded the day before the start of the experimental period on $\mathrm{d} 1$, at which time catheters were inserted into the jugular vein with a blood sample taken before catheter placement. All IV infusions were administered via jugular catheter at a constant rate over a 1 -h period on $\mathrm{d} 1$ and 2 of the experimental period. Approximately 350 $\mathrm{mL}$ of rumen-fluid samples were collected via cannula from each of the cows receiving rumen doses of 5-HTP before experimental dosing; doses of 5-HTP were then thoroughly mixed in approximately $350 \mathrm{~mL}$ of collected rumen fluid and vigorously shaken for approximately 30 min to allow 5-HTP to mix into solution. Fifteen minutes before the end of IV infusion, 5-HTP solution was manually dosed within the fiber mat of the rumen via the cannula as a single dose. Whole blood was collected from the jugular catheter before dosing on the first day of 5-HTP administration and approximately 1 $\mathrm{h}$ after treatment. Whole blood was collected before the second experimental dosing and then serially from the 


\begin{tabular}{|c|c|c|c|c|c|c|c|}
\hline Infusion $(1 \mathrm{~h})$ & Infusion (1 h) & $15 \mathrm{~min}$ & $30 \mathrm{~min}$ & Hourly & $4 \mathrm{~h}$ & $8 \mathrm{~h}$ & \\
\hline & & $4 \mathrm{~h}$ & $4 \mathrm{~h}$ & $16 \mathrm{~h}$ & & & \\
\hline Day 1 & & Day & & & Day 3 & Day 4 & Washout (7 d) \\
\hline
\end{tabular}

Experimental Period

Figure 1. Schematic representation of the experimental design and sampling timeline. Four experimental dosings of 5-hydroxy-L-tryptophan (5-HTP; $0 \mathrm{mg} / \mathrm{kg}$ of BW of 5-HTP, $1 \mathrm{mg} / \mathrm{kg}$ of BW of intraruminal 5-HTP, $2 \mathrm{mg} / \mathrm{kg}$ of BW of intraruminal 5-HTP, and $1 \mathrm{mg} / \mathrm{kg}$ of BW of intravenous 5-HTP) were administered to 4 multiparous Holstein dairy cows in a replicated $4 \times 4$ Latin square design.

jugular catheter post the second experimental dosing on d 2. Immediately after end of IV infusion (saline or IV 5-HTP), blood was collected every $15 \mathrm{~min}$ for the first $4 \mathrm{~h}$, every $30 \mathrm{~min}$ for the following $4 \mathrm{~h}$, and then hourly until $24 \mathrm{~h}$ post-termination of IV infusion. On d 3 of the experimental period, blood samples were collected every $4 \mathrm{~h}$ for $24 \mathrm{~h}$. On d 4 of the experimental period, blood samples were collected every $8 \mathrm{~h}$ for $24 \mathrm{~h}$ (Figure 1).

Whole blood was collected in 10-mL BD Vacutainer K2 EDTA Plus (368589, BD, Franklin Lakes, NJ) collection tubes and inverted gently. Immediately following inversion, 3 to $4 \mathrm{~mL}$ of whole blood was transferred from the 10-mL tube into a 5-mL Eppendorf tube (Hamburg, Germany) preloaded with approximately 35 $\mathrm{mg}$ of ascorbic acid $(10 \mathrm{mg} / \mathrm{mL})$ to stabilize and protect against oxidative loss of serotonin. The 5 -mL tube was mixed gently by inverting several times and frozen at $-20^{\circ} \mathrm{C}$ until analysis for serotonin concentration. Serotonin concentrations were analyzed in whole blood via Serotonin EIA (IM1749, Immunotech, Beckman Coulter, Brea, CA) according to manufacturer's instructions. All samples were diluted 1:100 to fit within the range of the assay's standard curve with the dilution buffer supplied by the kit. The intra- and interassay coefficients of variation were $3.25 \%$ and $16.27 \%$, respectively. Data were analyzed using the MIXED procedure of SAS (version 9.4, SAS Institute Inc., Cary, NC). Fixed terms in the model for serotonin concentration included treatment, hour, square, period, and treatment $\times$ hour. Hour was considered the repeated measure, and to account for autocorrelated errors, the spatial power structure was used within the SAS MIXED procedure. Days were analyzed separately to allow for correlation within day to determine the immediate effect of treatment. Fixed terms in the model for BW included treatment, period, and square. Fixed terms in the model for DMI included treatment, period, square, and day. Day was considered the repeated measure and the ar(1) structure was used within the MIXED procedure to account for autocorrelated errors. The random statements in all models included cow (square) and period $\times$ treatment $\times$ cow (square). The residuals from the models were analyzed with a normality test, and when the assumption of normality failed, ranks of the data were analyzed in a nonparametric matter. Rank transformation of serotonin concentrations were conducted using PROC RANK, and ranks of data were analyzed with the stated model, rather than the original data, to prevent violations of normality. Least squares means are reported for each variable, and statistical significance was declared at $P$ $\leq 0.05$. Mean comparisons for all measurements were performed using the Tukey test when treatment effects were significant.

We observed no differences $(P>0.05)$ between circulating serotonin concentrations on $\mathrm{d} 1$ of the experimental period between treatments (Table 1). Whole blood serotonin concentrations were elevated on d $2(P$ $=0.03)$ in cows receiving $2 \mathrm{mg} / \mathrm{kg}$ IR 5 -HTP compared with $0 \mathrm{mg} / \mathrm{kg} 5$-HTP (Figure 2). Circulating serotonin concentrations remained elevated in cows receiving 2 $\mathrm{mg} / \mathrm{kg}$ IR 5-HTP for approximately $18 \mathrm{~h}$ after treatment relative to both $0 \mathrm{mg} / \mathrm{kg} 5-\mathrm{HTP}$ and $1 \mathrm{mg} / \mathrm{kg}$ IR 5 -HTP. Interestingly, on d 3 and 4 of the experimental period, there were no differences between any of the IR 5 -HTP doses or $0 \mathrm{mg} / \mathrm{kg} 5$-HTP $(P>0.05)$. The $1 \mathrm{mg} /$ $\mathrm{kg}$ IV 5-HTP increased circulating serotonin concentrations relative to all other treatments on $\mathrm{d} 2,3$, and 4 of the experimental period $(P<0.05)$. The extended increase in serotonin after IV 5-HTP administration is similar to previous studies conducted in our laboratory (Weaver et al., 2016; Slater et al., 2018). Experimental BW means were not different between any treatment groups during the duration of the study $(P>0.05$; Table 1). We observed no differences in DMI between treatment groups $(P>0.05$; Table 1$)$; however, an effect of day was observed $(P=0.0001$; Table 1$)$. Dry matter intakes were lower at the beginning of the experimental period, which may be due to infusions and intensive sampling schedule occurring during that time.

Due to the ability of 5-HTP to improve calcium metabolism, usage of the serotonin precursor as a therapeutic management strategy for hypocalcemia prevention is of growing interest. Although this study used 
Table 1. Average $^{1}$ serotonin concentrations, BW, and feed intake from dry, nonpregnant cows provided different experimental doses of 5-hydroxy-L-tryptophan (5-HTP)

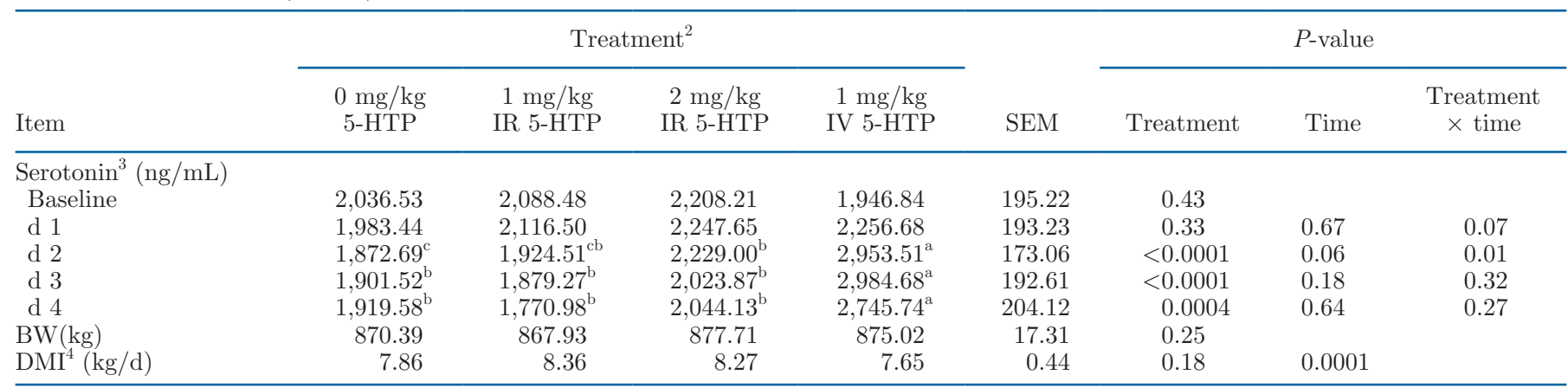

${ }^{\mathrm{a}-\mathrm{c}}$ Means within a row with different superscripts differ $(P<0.05)$.

${ }^{1}$ Results are expressed as LSM.

${ }^{2} 0 \mathrm{mg} / \mathrm{kg} 5-\mathrm{HTP}=0 \mathrm{mg} / \mathrm{kg}$ of BW of 5 -HTP; $1 \mathrm{mg} / \mathrm{kg}$ IR 5 -HTP $=1 \mathrm{mg} / \mathrm{kg}$ of BW of 5 -HTP dosed intraruminally; $2 \mathrm{mg} / \mathrm{kg}$ IR 5 -HTP $=2$ $\mathrm{mg} / \mathrm{kg}$ of BW of 5 -HTP dosed intraruminally; $1 \mathrm{mg} / \mathrm{kg}$ IV $5-\mathrm{HTP}=1 \mathrm{mg} / \mathrm{kg}$ of BW of 5 -HTP dosed intravenously.

${ }^{3}$ Serotonin concentrations represent mean value of all observations within day. Baseline serotonin represent samples taken before treatment administration and catheterization of each period.

${ }^{4} \mathrm{DMI}$ was recorded daily.

dry, nonpregnant dairy cows, which have a very different metabolism and physiology than peripartal dairy cows (hormonal status, DMI, energetic, and calcemic demand), these findings are the first to report intraruminal dosing of 5-HTP and a corresponding alteration in circulating serotonin, suggesting a possible use of 5 -HTP orally in ruminants. The elevation in circulating serotonin on d 2 after $2 \mathrm{mg} / \mathrm{kg}$ IR 5 -HTP over $0 \mathrm{mg} / \mathrm{kg}$ 5 -HTP may potentially reflect the transient passage of 5-HTP from the rumen with the liquid digesta.

The lack of decline and corresponding maintenance of circulating serotonin occurred in cows receiving some form of 5-HTP, which suggests part of the elevation in serotonin concentrations in $2 \mathrm{mg} / \mathrm{kg}$ IR 5 -HTP over 0 $\mathrm{mg} / \mathrm{kg} 5$-HTP may be related to lack of potential factors upstream inhibiting serotonin synthesis. Synthesis of serotonin can be altered by cortisol excess, vitamin $\mathrm{B}_{6}$ deficiency, and biochemical feedback, with 5-HTP usage avoiding these inhibition factors as it bypasses L-tryptophan conversion and corresponding factors (Meyers, 2000; Javelle et al., 2020). We did not observe treatment differences in feed intake, but the lowest DMI was recorded on $\mathrm{d} 2$. Therefore, precursor supply and gut serotonin synthesis and secretion may also be influencing factors in $0 \mathrm{mg} / \mathrm{kg} 5-\mathrm{HTP}$, as no form of 5-HTP was administered to mitigate inhibition factors. These influencing factors in $2 \mathrm{mg} / \mathrm{kg}$ IR 5 -HTP over 2 consecutive days may have allowed for an absence of decline and corresponding maintenance of circulating serotonin, which did not occur in $0 \mathrm{mg} / \mathrm{kg} 5$-HTP. Interestingly, circulating serotonin in the $2 \mathrm{mg} / \mathrm{kg}$ IR 5 -HTP had a clear separation compared with the $1 \mathrm{mg} /$ $\mathrm{kg}$ IR 5 -HTP and $0 \mathrm{mg} / \mathrm{kg} 5$-HTP across the early portion of the sampling period on $\mathrm{d} 2$, reaching peak serotonin at 840 min on $\mathrm{d} 2$ and then experiencing a steady decline. These findings suggest inhibition factors of serotonin may play a role in the pattern of serotonin concentrations observed in the $2 \mathrm{mg} / \mathrm{kg}$ IR 5 -HTP as they progress away from dosing and then continually fall across the experimental period. Further understanding of the metabolism and feedback when administering 5-HTP is needed to elucidate the mechanism of the observed maintenance of circulating serotonin and elevation in $2 \mathrm{mg} / \mathrm{kg}$ IR 5 -HTP. No treatment differences were detected on d 1 of 5-HTP administration in this study, which corresponded with previous data showing that both oral and IV treatment of 5-HTP in dairy animals requires 2 dosings before observing a measurable increase in circulating serotonin concentrations (Laporta et al., 2015; Marrero et al., 2019). Data from human literature has demonstrated that oral supplementation of 5-HTP is a clinically effective way to increase circulating serotonin; in addition, oral 5-HTP dose administration in preweaned calves has also been shown to increase serotonin concentrations in blood (Hernandez-Castellano et al., 2018; Marrero et al., 2019). However, these studies were conducted in humans and preweaned calves, which are considered nonruminants.

A similar study researching the AA methionine showed a definitive acute elevation in circulating methionine in response to ruminal dosing (Koenig et al., 2002). Several methods of protecting AA exist due to the degradation of AA by rumen microbes. One AA protection method used within the industry is chemical manipulation of the AA by adding a hydroxyl group (methionine hydroxy analog). Interestingly, 5-HTP is considered a modified AA, as it is a hydroxylated de- 

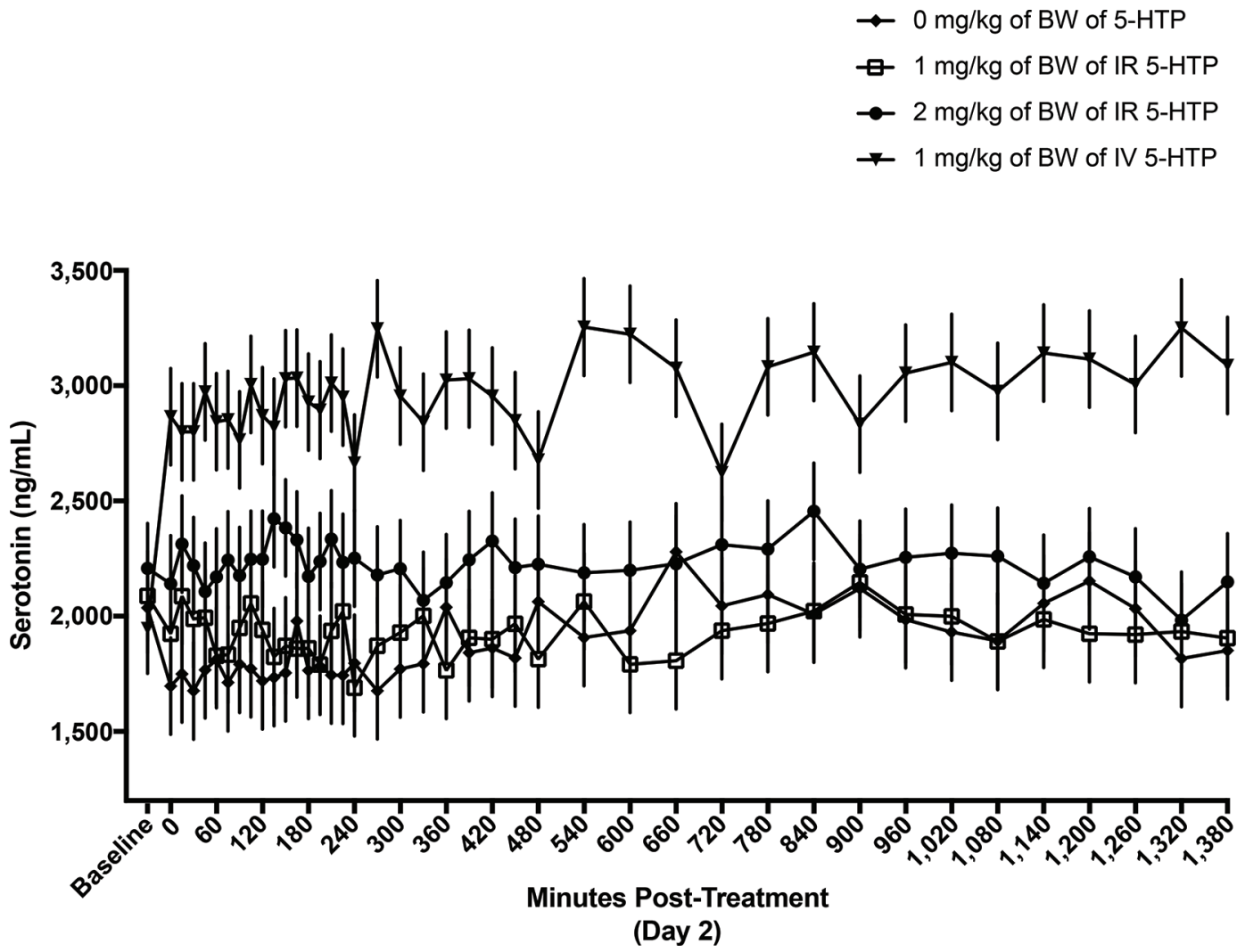

Figure 2. Whole blood serotonin concentrations on d 2 in cows following treatment with $0 \mathrm{mg} / \mathrm{kg}$ of BW of 5-hydroxy-L-tryptophan (5HTP), $1 \mathrm{mg} / \mathrm{kg}$ of BW of intraruminal (IR) 5 -HTP, $2 \mathrm{mg} / \mathrm{kg}$ of BW of IR 5-HTP, or $1 \mathrm{mg} / \mathrm{kg}$ of BW of intravenous (IV) 5-HTP. Values differ for serotonin concentration (treatment: $P<0.0001$, time: $P=0.06$, treatment $\times$ time: $P=0.01$ ). All values are reported as LSM and error bars represent SEM.

rivative of tryptophan. The additional hydroxyl group attached to the methionine has been thought to aid in resistance to microbial degradation, as the deaminative enzymes responsible for AA degradation are not effective (Koenig et al., 2002). Research has demonstrated that the hydroxy analog of methionine is more resistant to microbial degradation by microbes than free methionine (Patterson and Kung, 1988). Evidence on the rate of degradation of the AA tryptophan has been shown to be variable, but is thought to be degraded at a slower rate in the rumen relative to other AA (Mohammed et al., 2003).

In summary, this experiment presents preliminary evidence suggesting that $2 \mathrm{mg} / \mathrm{kg}$ of BW of 5 -HTP administered intraruminally elevates circulating serotonin concentrations in the dairy cow on d 2 of 5 -HTP administration. It is important to note that the serotonin concentration of the $2 \mathrm{mg} / \mathrm{kg}$ IR 5 -HTP dose is lower than the circulating serotonin concentrations previously shown in our laboratory's research studying serotonin's effect on calcium metabolism with IV infusion of 5-HTP. Future feeding experiments evaluating direct feed supplementation, length of supplementation, and optimal dosing rate need to be further researched to determine the most beneficial 5-HTP supplementation rate to increase circulating serotonin concentrations sufficiently for potential use as a mitigation tool for hypocalcemia.

\section{ACKNOWLEDGMENTS}

This project was funded by Amelgo, LLC (Covington, KY). The authors thank Derek Donnelly, Tatiana Munoz, Marissa Klister, Megan Lauber and the staff at the Dairy Cattle Center (Madison, WI) for their help with conduction of this experiment. The authors would also extend thanks to Vita Plus Corporation for financial support by a student fellowship. The authors have no conflicts of interest.

\section{REFERENCES}

Berger, M., J. A. Gray, and B. L. Roth. 2009. The expanded biology of serotonin. Annu. Rev. Med. 60:355-366. https://doi.org/10.1146/ annurev.med.60.042307.110802.

Birdsall, T. C. 1998. 5-Hydroxytryptophan: A clinically-effective serotonin precursor. Altern. Med. Rev. 3:271-280. 
Goff, J. P., K. Kimura, and R. L. Horst. 2002. Effect of mastectomy on milk fever, energy, and vitamins A, E, and $\beta$-carotene status at parturition. J. Dairy Sci. 85:1427-1436. https://doi.org/10.3168/ jds.S0022-0302(02)74210-0.

Hernandez-Castellano, L. E., R. Ozcelik, L. L. Hernandez, and R. M. Bruckmaier. 2018. Short communication: Supplementation of colostrum and milk with 5-hydroxy-l-tryptophan affects immune factors but not growth performance in newborn calves. J. Dairy Sci. 101:794-800. https://doi.org/10.3168/jds.2017-13501.

Javelle, F., A. Lampit, W. Bloch, P. Hausserman, S. Johnson, and P. Zimmer. 2020. Effects of 5-hydroxytryptophan on distinct types of depression: A systematic review and meta-analysis. Nutr. Rev. 78:77-78.

Koenig, K. M., L. M. Rode, C. D. Knight, and M. C. Vazquez-Anon. 2002. Rumen degradation and availability of various amounts of liquid methionine hydroxy analog in lactating dairy cows. J. Dairy Sci. 85:930-938. https://doi.org/10.3168/jds.S0022-0302(02)74151 -9 .

Kollmann, M. T., M. Locher, F. Hirche, K. Eder, H. H. D. Meyer, and R. M. Bruckmaier. 2008. Effects of tryptophan supplementation on plasma tryptophan and related hormone levels in heifers and dairy cows. Domest. Anim. Endocrinol. 34:14-24. https://doi.org/ 10.1016/j.domaniend.2006.09.005

Laporta, J., J. J. Gross, T. D. Crenshaw, R. M. Bruckmaier, and L. L. Hernandez. 2014. Short Communication: Timing of first milking affects serotonin (5-HT) concentrations. J. Dairy Sci. 97:2944-2948. https://doi.org/10.3168/jds.2013-7336.

Laporta, J., S. A. Moore, M. W. Peters, T. L. Peters, and L. L. Hernandez. 2013. Short communication: Circulating serotonin (5-HT) concentrations on day 1 of lactation as a potential predictor of transition-related disorders. J. Dairy Sci. 96:5146-5150. https:// doi.org/10.3168/jds.2013-6718.

Laporta, J., S. A. E. Moore, S. R. Weaver, C. M. Cronick, M. Olsen, A. P. Prichard, B. P. Schnell, T. D. Crenshaw, F. Penagaricano, R. M. Bruckmaier, and L. L. Hernandez. 2015. Increasing serotonin concentrations alter calcium and energy metabolism in dairy cows. J. Endocrinol. 226:43-55. https://doi.org/10.1530/JOE-14-0693.

Lavoie, B., J. B. Lian, and G. M. Mawe. 2017. Regulation of bone metabolism by serotonin. Adv. Exp. Med. Biol. 1033:35-46. https: //doi.org/10.1007/978-3-319-66653-2_3.

Magnussen, I., T. S. Jensen, J. H. Rand, and M. H. Van Woert. 1981. Plasma accumulation of metabolism of orally administered single dose L-5-hydroxytryptophan in man. Acta Pharmacol. Toxicol. (Copenh.) 49:184-189. https://doi.org/10.1111/j.1600-0773.1981 .tb00890.x.
Magnussen, I., and F. Nielsen-Kudsk. 1980. Bioavailability and related pharmacokineticsin man of orally administered L-5-hydroxytryptophan in a steady state. Acta Pharmacol. Toxicol. (Copenh.) 46:257-262. https://doi.org/10.1111/j.1600-0773.1980.tb02451.x.

Marrero, M. G., B. Dado-Senn, S. L. Field, D. R. da Silva, A. L. Skibiel, and J. Laporta. 2019. Increasing serotonin bioavailability in preweaned dairy calves impacts hematology, growth, and behavior. Domest. Anim. Endocrinol. 69:42-50. https://doi.org/10.1016/j .domaniend.2019.04.007.

Meyers, S. 2000. Use of neurotransmitter precursors for treatment of depression. Altern. Med. Rev. 5:64-71.

Mohammad-Zadeh, L. F., L. Moses, and S. M. Gwaltney-Brant. 2008. Serotonin: A review. J. Vet. Pharmacol. Ther. 31:187-199. https:/ /doi.org/10.1111/j.1365-2885.2008.00944.x.

Mohammed, N., R. Onodera, and M. M. Or-Rashid. 2003. Degradation of tryptophan and related indolic compounds by ruminal bacteria, protozoa and their mixture in vitro. Amino Acids 24:73-80. https://doi.org/10.1007/s00726-002-0330-8.

Patterson, J. A., and L. Kung Jr.. 1988. Metabolism of DL-methionine and methionine analogs by rumen microorganisms. J. Dairy Sci. 71:3292-3301. https://doi.org/10.3168/jds.S0022-0302(88)79934 $-8$.

Slater, C. J., E. L. Endres, S. R. Weaver, A. A. Cheng, M. R. Lauber, S. F. Endres, E. Olstad, A. DeBruin, P. M. Crump, E. Block, and L. L. Hernandez. 2018. Interaction of 5-hydroxy-L-tryptophan and negative dietary cation-anion difference on calcium homeostasis in multiparous peripartum dairy cows. J. Dairy Sci. 101:5486-5501. https://doi.org/10.3168/jds.2017-13938.

Walther, D. J., and M. Bader. 2003. A unique central tryptophan hydroxylase isoform. Biochem. Pharmacol. 66:1673-1680. https:// doi.org/10.1016/S0006-2952(03)00556-2.

Weaver, S. R., A. P. Prichard, E. L. Endres, S. A. Newhouse, T. L. Peters, P. M. Crump, M. S. Akins, T. D. Crenshaw, R. M. Bruckmaier, and L. L. Hernandez. 2016. Elevation of circulating serotonin improves calcium dynamics in the peripartum dairy cow. J. Endocrinol. 230:105-123. https://doi.org/10.1530/JOE-16-0038.

\section{ORCIDS}

M. K. Connelly @ https://orcid.org/0000-0001-8209-9523

L. L. Hernandez @ https://orcid.org/0000-0001-7591-5203 